\title{
Optimizing the Phosphorus Concentration and Duration of Seedling Dipping in Soil Slurry for Accelerating the Initial Growth of Transplanted Rice
}

\author{
Aung Zaw Oo ${ }^{1}$, Yasuhiro TSUJIMOTO ${ }^{1, * \mathbb{D}}$ and Njato Mickaël RAKOTOARISOA ${ }^{2}$ \\ 1 Japan International Research Center for Agricultural Sciences, 1-1 Ohwashi, Tsukuba, Ibaraki 3058686, Japan; \\ aungzawoo@affrc.go.jp \\ 2 Département de Recherche Rizicoles (DRR), Centre National de Recherche Appliquée au Développement \\ Rural (FOFIFA), BP 1690, Tsimbazaza, Antananarivo 101, Madagascar; njatomichael@yahoo.fr \\ * Correspondence: tsjmt@affrc.go.jp; Tel./Fax: +81-29-838-6367
}

Received: 13 January 2020; Accepted: 2 February 2020; Published: 6 February 2020

\begin{abstract}
Given the finite nature of $P$ fertilizer resources, it is imperative to investigate effective $P$ management practices in order to achieve sustainable rice production. This study was conducted (1) to assess the effect of dipping rice seedlings in P-enriched slurry before transplanting (P-dipping, hereafter) on initial plant growth and (2) to determine the optimum $\mathrm{P}$ concentration and dipping duration. In the P-dipping treatments, four $\mathrm{P}_{2} \mathrm{O}_{5}$ concentrations in the slurry $(4.3 \%, 5.0 \%, 6.0 \%$, and $7.5 \%)$ and four dipping durations $(0.5 \mathrm{~h}, 2 \mathrm{~h}, 4 \mathrm{~h}$, and $8 \mathrm{~h})$ were investigated. After the treatments, the seedlings were transplanted into $1 / 5000$ Wagner pots and grown under flooded conditions for 42 days and they were compared with plants under conventional $\mathrm{P}$ incorporation at the rate of $300 \mathrm{mg} \mathrm{P}_{2} \mathrm{O}_{5}$ pot $^{-1}$ and with plants under no $\mathrm{P}$ application. The amount of $\mathrm{P}_{2} \mathrm{O}_{5}$ attached to P-dipped seedlings, or locally applied in the rhizosphere at transplanting, increased with higher $\mathrm{P}$ concentrations in the slurry, ranging from 87.5 to $112.2 \mathrm{mg} \mathrm{pot}^{-1}$. Shoot biomass at 42 days after transplanting (DAT) was greatly increased in plants under the P-dipping treatments, compared to that in plants with no $\mathrm{P}$ application and was comparable to or greater than that in plants under conventional $\mathrm{P}$ incorporation, even when P levels were 2.5 to 3 times lower. Among the P-dipping treatments, we observed some significant effects of $\mathrm{P}$ concentrations and dipping durations on seedling $\mathrm{P}$ uptake and shoot biomass, without any interaction between these variables. Seedling $\mathrm{P}$ uptake and biomass tended to be higher with higher $\mathrm{P}$ concentrations in slurry and longer dipping durations. Conversely, the shoot biomass at 42 DAT was significantly lower in plants under the highest $\mathrm{P}$ concentration treatment $\left(7.5 \% \mathrm{P}_{2} \mathrm{O}_{5}\right)$ compared to that in other plants and tended to be lower with longer dipping durations ( $4 \mathrm{~h}$ and $8 \mathrm{~h}$ ). These negative effects can be attributed to the slow recovery from transplanting shock because of the chemical damage of seedlings exposed to higher salt concentrations for longer durations. The present study highlights that (1) P-dipping could be an effective approach to increase transplanted rice production with minimal $\mathrm{P}$ inputs, and (2) this effect could be higher with a low P-concentration in the slurry $\left(4.3 \% \mathrm{P}_{2} \mathrm{O}_{5}\right)$ and a short dipping duration $(0.5 \mathrm{~h})$. Based on the obtained results, further on-farm trials are expected to assess farmers' appreciation and the potential constraints of adopting this technique.
\end{abstract}

Keywords: localized application; Oryza sativa L.; P-dipping; P use efficiency; salt stress

\section{Introduction}

Phosphorus deficiency is one of the main constraints for rice production in many parts of the world [1-3]. In order to overcome this problem, recommended or even excess amounts of $P$ fertilizer 
are usually applied to obtain high grain yields. However, world resources of $\mathrm{P}$ are finite and thus, $\mathrm{P}$ should be used as efficiently as possible in order to conserve the base resources [4]. Efficient $P$ fertilizer management is also key to improving rice yield for smallholder farmers who use few external inputs, such as in the case of Sub-Saharan Africa [5]. Therefore, it is necessary to find appropriate strategies for the effective use of $\mathrm{P}$ fertilizers in rice production systems.

In this respect, micro-dosed and localized $\mathrm{P}$ applications were examined in several crops by applying $\mathrm{P}$ fertilizer in root zones where $\mathrm{P}$ is readily accessible to the plants, instead of conventional application via broadcasting or incorporation. Studies reported that this technique increases rice yield and improves $\mathrm{P}$ fertilizer use efficiency, particularly in P-deficient soils in the tropics, e.g., placement of $\mathrm{P}$ in a planting hole for the upland rice production system $[3,6-8]$ and application to a nursery bed for the lowland rice production system $[9,10]$.

Likewise, dipping seedling roots into P-enriched slurry just before transplanting (P-dipping) may also improve $P$ fertilizer use efficiency in transplanted lowland rice production systems. Previous studies on P-dipping reported an increase in grain yield by $10 \%-50 \%$ with the same $\mathrm{P}$ application rates, or plants achieving the same yield levels with $40 \%-60 \%$ reductions in $\mathrm{P}$ application rates, relative to broadcasting or incorporating $\mathrm{P}$ at transplanting [11-15]. These empirical observations suggest that P-dipping should attract further attention as a considerable approach for sustainable yield increases with minimal P inputs. However, most of these studies were reported in institutional documents/newsletters or were partially cited in book chapters which provided little information on treatment aspects such as durations of dipping and P concentrations in enriched slurry. Such information is critically important to farmers who apply the P-dipping technique in their fields. The only study which assessed the application rate and duration of dipping was by Kalidas-Singh and Thakuria [15]. Their assessments were based on the P concentrations in seedlings after dipping, but not on biomass growth after transplanting. We consider that it is important to assess the P-dipping technique, based not only on its effect on the seedling nutrient status, but also on the initial biomass production after the treatment. Therefore, this study aimed (1) to confirm the effect of the P-dipping technique relative to P broadcasting and (2) to identify the optimum $P$ concentrations in slurry and the optimal dipping durations, in terms of the biomass production and $\mathrm{P}$ uptakes at the early growth stages after transplanting.

\section{Materials and Methods}

\subsection{Preparation of P-Enriched Slurries and Dipping of Rice Seedlings}

The experiment was conducted in a greenhouse at the Japan International Research Center for Agricultural Science (JIRCAS, Tsukuba, Japan). The temperature inside the greenhouse was controlled by an automatic ventilation system in a basic manner, i.e., windows opened at the temperature $>30^{\circ} \mathrm{C}$ and closed at the temperature $<25^{\circ} \mathrm{C}$. The daily mean temperature in the greenhouse ranged from $25.6{ }^{\circ} \mathrm{C}$ to $32.9^{\circ} \mathrm{C}$ during the pot experiment (Thermo Recorder TR-50U2, T\&D Corporation, Nagano, Japan). The volcanic soil was collected from the forest subsoil (20 to $40 \mathrm{~cm}$ layer) within the experimental farm of JIRCAS in order to ensure the absence of the potential effects of P-fertilization records. The soils were first air-dried and passed through a $2.0 \mathrm{~mm}$ sieve, and then used to prepare P-enriched slurry and to grow rice in pots. The experimental soil was sandy loam with a high $\mathrm{P}$ retention capacity of $99 \%$. The other properties of the experimental soils are summarized in Table 1.

Based on the application rates in the previous P-dipping studies [13,14], $6.52 \mathrm{~g}$ of triple super phosphate (TSP) was mixed with different amounts of soil (70, 60, 50, and $40 \mathrm{~g}$ of air-dried soil) in order to obtain different $\mathrm{P}$ concentrations in the soil slurry $\left(4.3 \% \mathrm{P}_{2} \mathrm{O}_{5}(\mathrm{~S} 1), 5 \% \mathrm{P}_{2} \mathrm{O}_{5}(\mathrm{~S} 2), 6 \% \mathrm{P}_{2} \mathrm{O}_{5}\right.$ (S3), and 7.5\% $\mathrm{P}_{2} \mathrm{O}_{5}$ (S4), respectively). Water was added in the ratio of 2.5:1 (air-dried soil:water) and thoroughly mixed in to make a P-enriched slurry. 
Table 1. Physicochemical properties of soil.

\begin{tabular}{cc}
\hline Parameters & \\
\hline $\mathrm{pH}\left(1: 2.5 \mathrm{H}_{2} \mathrm{O}\right)$ & 5.7 \\
$\mathrm{EC}\left(\mathrm{dS} \mathrm{m}^{-1}\right)$ & 0.04 \\
Total $\mathrm{N}\left(\mathrm{g} \mathrm{kg}^{-1}\right)^{\mathrm{a}}$ & 1.8 \\
${\text { Total C }\left(\mathrm{g} \mathrm{kg}^{-1}\right)^{\mathrm{a}}}^{\mathrm{a}}$ & 45.5 \\
${\mathrm{P} \mathrm{retention}(\%)^{\mathrm{b}}}$ & 99.0 \\
$\mathrm{P}_{\text {oxalate }}\left(\mathrm{g} \mathrm{kg}^{-1}\right)^{\mathrm{c}}$ & 4.0 \\
$\mathrm{Al}_{\text {oxalate }}\left(\mathrm{g} \mathrm{kg}^{-1}\right)^{\mathrm{c}}$ & 46.1 \\
$\mathrm{Fe}_{\text {oxalate }}\left(\mathrm{g} \mathrm{kg}^{-1}\right)^{\mathrm{c}}$ & 25.7 \\
Sand $(\%)^{\mathrm{d}}$ & 83.4 \\
Silt $(\%)^{\mathrm{d}}$ & 10.5 \\
Clay (\%) & 6.1 \\
Texture & Loamy sand \\
\hline
\end{tabular}

a: NC analyzer, Sumigraph NC-220F (SCAS, Tokyo, Japan). b: The proportion of absorbed P amounts after shaking $5 \mathrm{~g}$ of soil and $25 \mathrm{~mL}$ of $1000 \mathrm{ppm}$ P solution for $24 \mathrm{~h}$. c: Inductively coupled plasma mass spectrometer (ICPE-9000, Shimazu, Japan) after oxalate extraction. d: Sieving and pipetting method.

After the preparation of soil slurries with different $\mathrm{P}$ concentrations, the roots of 50 rice seedlings (21 days old, Oryza sativa L. var. IR64) were dipped in the slurry for four dipping durations $(0.5 \mathrm{~h}, 2 \mathrm{~h}$, $4 \mathrm{~h}$, and $8 \mathrm{~h}$ ). All treatment combination experiments were done in quadruplicate. At transplanting, any soil slurries naturally attached to two seedlings were sampled twice and carefully collected into an aluminum cup by washing off the seedling roots. Then, the amounts of soil slurry and $\mathrm{P}$ transferred with two seedlings per pot were estimated by oven-drying the slurry samples at $105^{\circ} \mathrm{C}$ for $24 \mathrm{~h}$ and by multiplying the slurry amount by the P concentration for each replicate.

The rice seedlings were separately sampled in order to determine the dry weights at transplanting after oven-drying at $80^{\circ} \mathrm{C}$ for two days. The seedling's $\mathrm{P}$ concentration was determined with the molybdate blue method [16], after dry ashing at $550{ }^{\circ} \mathrm{C}$ for $2 \mathrm{~h}$ and digesting with $0.5 \mathrm{M} \mathrm{HCl}$. The seedling's $\mathrm{P}$ uptake ( $\mathrm{mg} \mathrm{pot}^{-1}$ ) was calculated by multiplying the $\mathrm{P}$ concentration and the dry weight.

\subsection{Pot Experiment}

The treated seedlings were transplanted into pots (two seedlings per hill, one hill per pot). The pots were filled with $3 \mathrm{~kg}$ of air-dried volcanic soil and watered (1:5000 Wenger pot, height $20 \mathrm{~cm}$, diameter $16 \mathrm{~cm}$ ). $\mathrm{P}$ was incorporated $\left(\mathrm{P}_{\text {inco. }}\right.$ ) at the rate of $300 \mathrm{mg} \mathrm{P}_{2} \mathrm{O}_{5}$ pot $^{-1}$ and control (Cont. - no P application) treatments were prepared in the same manner. For the $P_{\text {inco. }}$ treatments, all of the applied $\mathrm{P}$ was thoroughly mixed with soils in pots just before transplanting. In total, there were 72 pots and 18 treatments (four levels of $\mathrm{P}$ concentrations in the slurry combined with four dipping durations, $\mathrm{P}_{\text {inco. }}$ and Cont.) with four replications. In all the treatments, $\mathrm{NH}_{4} \mathrm{NO}_{3}$ and $\mathrm{K}_{2} \mathrm{SO}_{4}$ at the rates of $300 \mathrm{mg}$ $\mathrm{N} \mathrm{pot}^{-1}$ and $300 \mathrm{mg} \mathrm{K} \mathrm{pot}^{-1}$, respectively, were applied to the soil before transplanting in order to exclude the potential effects of $\mathrm{N}$ and $\mathrm{K}$ deficiencies.

The rice plants were grown in submerged conditions and harvested 42 days after transplanting (DAT). At harvest, the biomass and P concentrations of the shoots were determined using the same procedure as described above for the seedlings.

\subsection{Statistical Analysis}

The data were analyzed by a two-way analysis of variance (ANOVA) in order to assess the single and interaction effects of $\mathrm{P}$ concentrations in the slurry and dipping durations using STAR software (Statistical Tools for Agricultural Research, International Rice Research Institute, IRRI, Los Baños, the Philippines). The mean comparisons of the treatment were ascertained using Tukey's HSD test at 5\% and $1 \%$ probability levels. Then, the mean values of the P-dipping treatments were compared with 
those of the Cont. and $\mathrm{P}_{\text {inco. }}$ treatments using Tukey's HSD test. In this comparison, the S4 and long dipping durations ( $4 \mathrm{~h}$ and $8 \mathrm{~h}$ ) were excluded because of apparent salt stresses.

\section{Results}

\subsection{Effect of P-Dipping Treatments on the Seedlings}

The amount of $\mathrm{P}$ transferred with seedlings, or $\mathrm{P}$ concentratedly applied in the rhizosphere at transplanting, was significantly affected by the $\mathrm{P}$ concentrations in the slurry, but not by dipping durations (Figure 1). The amount of $\mathrm{P}_{2} \mathrm{O}_{5}$ transferred with seedlings ranged from $87.5 \mathrm{mg}$ to 112.2 mg per pot, and it was the highest in the slurry S4, followed by S3, S2, and S1 in the order of P concentrations in slurry. The amounts of $\mathrm{P}$ applied in the P-dipping treatments were $167.4 \%$ to $242.9 \%$ lower than that of the $\mathrm{P}_{\text {inco. }}$ treatment $\left(300 \mathrm{mg} \mathrm{P}_{2} \mathrm{O}_{5}\right.$ pot $\left.^{-1}\right)$.

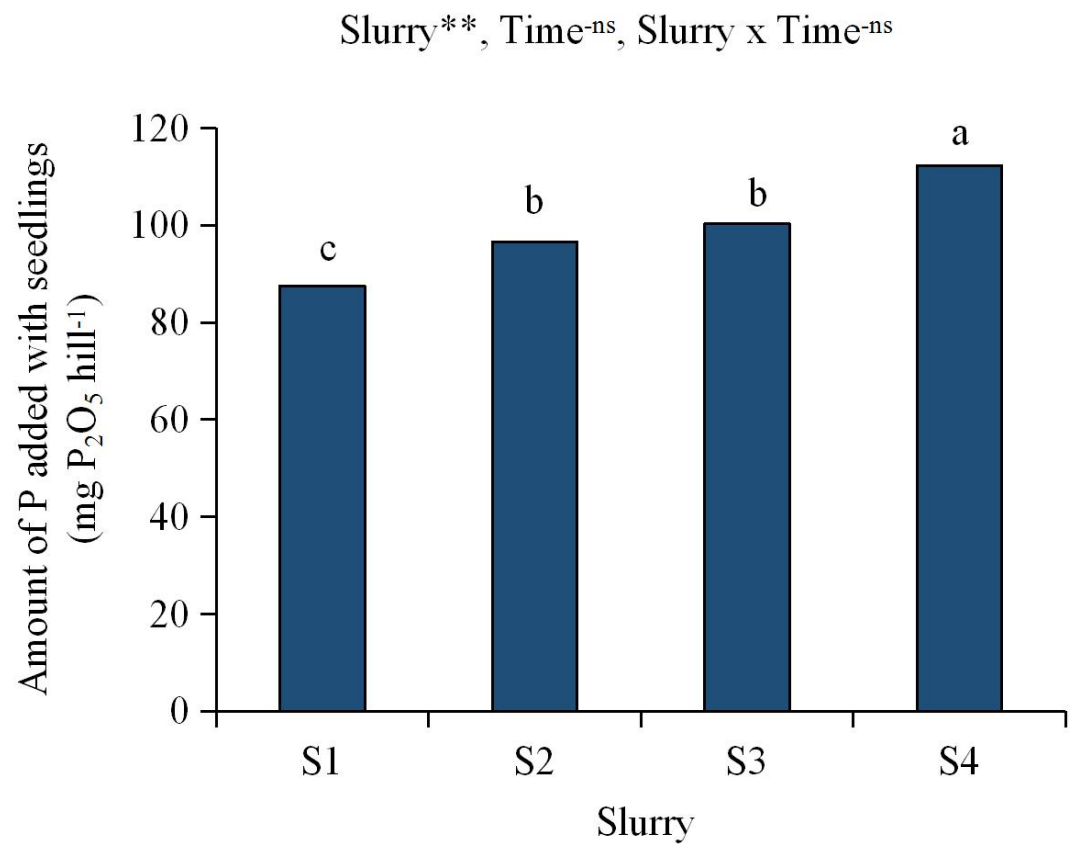

Figure 1. Effect of phosphorus concentration in slurry on the amount $\mathrm{P}$ added with seedlings at transplanting. ${ }^{* *} p<0.01, \mathrm{~ns}=$ not significant. The different letters within a column indicate significant differences between treatments at $p<0.05$ using Tukey's HSD test.

The seedling $\mathrm{P}$ concentration and seedling $\mathrm{P}$ uptake were significantly affected by both the $\mathrm{P}$ concentrations in the slurry and the dipping durations, with no interaction between the two (Table 2). The seedling P concentration increased with the increasing P concentrations in the slurry from $0.43 \%$ in S1 to $0.59 \%$ in S4, and these values were $48.3 \%-103.5 \%$ higher, respectively, than those in the seedlings without P-dipping treatment. Accordingly, seedling P uptake was the highest in S4, followed by S3, S2, and S1, and these values were $83.3 \%-150 \%$ greater than those in the seedlings without P-dipping treatments. Both seedling $\mathrm{P}$ concentration and uptake were significantly lower with the dipping durations of $0.5 \mathrm{~h}$ and $2 \mathrm{~h}$ than those of $4 \mathrm{~h}$ and $8 \mathrm{~h}$. The dipping duration of $4 \mathrm{~h}$ led to the highest $\mathrm{P}$ concentration and $\mathrm{P}$ uptake of seedlings. 
Table 2. Effect of P concentration in slurry and dipping duration on seedling P concentration, seedling $P$ uptakes, and shoot biomass and P uptakes at 42 DAT in comparison with Cont. and $P_{\text {inco. }}$ treatments.

\begin{tabular}{|c|c|c|c|c|}
\hline & $\begin{array}{c}\text { Seedling P } \\
\text { Concentration (\%) }\end{array}$ & $\begin{array}{l}\text { Seedling P Uptake } \\
\left(\mathrm{mg} \mathrm{plant}^{-1}\right)\end{array}$ & $\begin{array}{l}\text { Shoot Biomass } \\
\qquad\left(\mathrm{g} \mathrm{pot}^{-1}\right)\end{array}$ & $\begin{array}{l}\text { Shoot P Uptake } \\
\left(\mathrm{mg} \mathrm{pot}^{-1}\right)\end{array}$ \\
\hline \multicolumn{5}{|l|}{ P conc. in slurry } \\
\hline S1 & $0.43 c$ & $0.11 \mathrm{~b}$ & $11.62 \mathrm{a}$ & $8.81 \mathrm{ab}$ \\
\hline S2 & $0.47 \mathrm{bc}$ & $0.12 b$ & $11.48 \mathrm{a}$ & $9.87 \mathrm{a}$ \\
\hline S3 & $0.53 \mathrm{~b}$ & $0.14 \mathrm{a}$ & $11.26 \mathrm{a}$ & $9.81 \mathrm{a}$ \\
\hline S4 & $0.59 \mathrm{a}$ & $0.15 \mathrm{a}$ & $9.71 \mathrm{~b}$ & $8.15 b$ \\
\hline \multicolumn{5}{|l|}{ Dipping duration (h) } \\
\hline 0.5 & $0.42 c$ & $0.10 \mathrm{c}$ & $12.13 \mathrm{a}$ & $9.22 \mathrm{ab}$ \\
\hline 2 & $0.43 c$ & $0.10 \mathrm{c}$ & 11.88 a & $10.13 \mathrm{a}$ \\
\hline 4 & $0.61 \mathrm{a}$ & $0.17 \mathrm{a}$ & $9.00 \mathrm{~b}$ & $8.24 \mathrm{~b}$ \\
\hline 8 & $0.54 \mathrm{~b}$ & $0.15 \mathrm{~b}$ & $11.06 \mathrm{a}$ & $9.04 \mathrm{ab}$ \\
\hline \multicolumn{5}{|c|}{ Analysis of variance } \\
\hline P conc. in slurry & $* *$ & $* *$ & * & * \\
\hline Duration & $* *$ & $* *$ & $* *$ & * \\
\hline P conc. $\times$ duration & ns & ns & ns & ns \\
\hline \multicolumn{5}{|c|}{ Mean comparison among P-dipping, Cont., and $\mathrm{P}_{\text {inco. }}$} \\
\hline P-dipping + & $0.50 \mathrm{~A}$ & $0.13 \mathrm{~A}$ & $11.51 \mathrm{~A}$ & $9.48 \mathrm{~A}$ \\
\hline Cont. & $0.29 \mathrm{~B}$ & $0.06 \mathrm{~B}$ & $0.49 \mathrm{C}$ & $0.21 \mathrm{C}$ \\
\hline$P_{\text {inco. }}$ & - & - & $9.00 \mathrm{~B}$ & $6.69 \mathrm{~B}$ \\
\hline
\end{tabular}

${ }^{*} p<0.05,{ }^{* *} p<0.01$, ns $=$ not significant. In each column, different small letters within a column indicate significant differences between treatments at $p<0.05$ using Tukey's HSD test. † The mean value over P-dipping treatments except $4 \mathrm{~h}$ and $8 \mathrm{~h}$ dipping durations in $\mathrm{S} 4$ was compared with Cont. and $\mathrm{P}_{\text {inco. }}$ Different capital letters indicate significant differences among these treatments at $p<0.05$ using Tukey's HSD test.

\subsection{Early Growth and P Uptake of Rice}

The shoot biomass at 42 DAT was substantially increased in all P-dipping treatments ( 9.71 to $\left.11.62 \mathrm{~g} \mathrm{pot}^{-1}\right)$ compared to that in the Cont. $\left(0.49 \mathrm{~g} \mathrm{pot}^{-1}\right)$ (Table 2). Moreover, excluding the seedlings in the S4 treatments with dipping durations of $4 \mathrm{~h}$ and $8 \mathrm{~h}$, the seedlings in other P-dipping treatments had a significantly greater biomass, despite having much lower $\mathrm{P}$ application rates than that in the $\mathrm{P}_{\text {inco. }}\left(9.00 \mathrm{~g} \mathrm{pot}^{-1}\right)$. Likewise, the shoot $\mathrm{P}$ uptake was significantly increased with P-dipping compared to with $P_{\text {inco. }}\left(6.69 \mathrm{mg} \mathrm{pot}^{-1}\right)$.

Different $\mathrm{P}$ concentrations in the slurry and different dipping durations significantly affected both the shoot biomass and the shoot P uptake (Table 2). There were no interactions between the two. A significantly higher shoot biomass was observed in the slurries with lower P concentrations (S1, S2, and S3) compared to that in the slurry from S4. There was no significant difference in the shoot biomass between the S1, S2, and S3 treatments. Although the seedlings in S1 had significantly lower shoot $\mathrm{P}$ concentrations than the seedlings in the other treatments, shoot $\mathrm{P}$ uptake was comparable with that in the seedlings in the other slurry treatments because of the high biomass production. Shoot $\mathrm{P}$ uptake was the lowest in the seedlings in $\mathrm{S} 4$ because it had the lowest biomass production. In the treatments with the short dipping durations of $0.5 \mathrm{~h}$ and $2 \mathrm{~h}$, the seedlings tended to have a higher shoot biomass and higher shoot $\mathrm{P}$ uptakes the treatments with longer dipping durations. The plants in the treatment with the dipping duration of $4 \mathrm{~h}$ had the lowest shoot biomass and the lowest $\mathrm{P}$ uptake.

\section{Discussion}

Improved $\mathrm{P}$ fertilizer management is required for a sustainable increase in rice production while addressing the depletion of future P reserves. The pot experiment clearly demonstrated that initial biomass production can be greatly improved by dipping seedlings into a P-enriched slurry before transplanting, compared to an application with no $\mathrm{P}$, or compared to a $\mathrm{P}_{\text {inco. }}$ treatment. In the $\mathrm{P}_{\text {inco. }}$ treatment in this study, the amounts of $\mathrm{P}$ applied were $167.4 \%-242.9 \%$ higher than in the P-dipping 
treatments (Table 2, Figure 1). This result is consistent with previous observations which observed that P-dipping produced greater shoot biomass [17] and root biomass [15] from a very early growth stage after transplanting and eventually resulted in greater rice yields than those in conventional P application via broadcasting. Therefore, P-dipping can be considered as a potential approach to improve both applied P use efficiency and the production of rice in transplanted lowland systems.

More importantly, the experiment detected that both the seedling $\mathrm{P}$ concentration/P uptakes and the initial shoot biomass/P uptakes after transplanting were significantly affected by the P-concentrations in the slurry and were also affected by the dipping durations (Table 2). The seedling's P concentration/P uptakes tended to increase with higher P concentrations in the slurry and longer dipping durations (up to $4 \mathrm{~h}$ ), but the values were slightly reduced at $8 \mathrm{~h}$. This result was consistent with Kalidas-Singh et al. [15], which found that the seedling $\mathrm{P}$ concentration/P uptake increased with increased doses of $\mathrm{P}$ in the slurry and with longer dipping durations, and reached the maximum at a dose of $125 \mathrm{mg} \mathrm{P} \mathrm{kg}^{-1}$ soil and at a $12 \mathrm{~h}$ dipping, beyond which the values started to decrease. Based on these observations, they proposed the optimum $\mathrm{P}$ application dose of $125 \mathrm{mg} \mathrm{kg}^{-1}$ soil for slurry and optimum dipping duration of $10 \mathrm{~h}$ for the P-dipping technique, in order to maximize the seedling $\mathrm{P}$ concentration/P uptake. They argued that the additional $\mathrm{P}$ uptake in the seedlings might help develop robust root systems, explore more $\mathrm{P}$ in soils, and accelerate initial biomass growth after transplanting.

However, our results reveal that higher $P$ uptake and higher $P$ concentration in the seedlings under the P-dipping treatments did not necessarily lead to optimal biomass production after transplanting. There was rather an occurrence of rolling and drying leaves soon after transplanting, which was attributable to salt stress when seedlings were exposed to the highest $\mathrm{P}$ concentration in the slurry (S4) combined with the longer dipping durations ( $4 \mathrm{~h}$ and $8 \mathrm{~h}$ ). These adverse effects, despite the higher $\mathrm{P}$ uptake in the seedlings, slowed the recovery of the seedlings from transplanting shock and made the advantage of P-dipping less significant. None of the previous studies reported chemical injuries of rice seedlings with the application of the P-dipping technique, except that of Lu et al. [11], who stated that it is necessary to avoid any injuries to seedlings when dipping plants into nutrient-rich slurry. Our study is the first to observe that recovery from transplanting shock can be slowed when the seedlings are dipped in a high $\mathrm{P}$ concentration slurry and left inside for a long time. In addition, the results of the different dipping duration treatments imply that the key effect of P-dipping is ascribed not to the development of P-enriched seedlings but to concentrated $\mathrm{P}$ transfer with seedlings in the rhizosphere at transplanting. It should be noted, however, that the P-dipping with the highest concentration in the slurry and the longer dipping durations still produced equivalent biomasses to those of $P_{\text {inco. }}$ with smaller $\mathrm{P}$ application rates.

The P-dipping with either lower P concentrations in the slurry or shorter durations were more advantageous to rice biomass. This finding is important as shorter dipping durations would make it more practical for smallholder farmers to apply this technique. Moreover, in order to avoid the potential salt stresses, $\mathrm{P}$-dipping in $4.3 \%-5.0 \% \mathrm{P}_{2} \mathrm{O}_{5}$ slurry for $0.5 \mathrm{~h}$ is the recommended practice to improve both $\mathrm{P}$ use efficiency and biomass production of transplanted rice. Our concomitant on-farm trial demonstrated significant increases in initial biomass production and grain yields, obtained by dipping the seedlings in approximately $5.0 \% \mathrm{P}_{2} \mathrm{O}_{5}$ slurry for $0.5 \mathrm{~h}$ before transplanting, relative to those in seedlings under P broadcasting in highly P-deficient soils in Madagascar [17]. It should be noted that we used a single soil type with high P retention capacity (99\%). Further studies are expected, using various soils to clarify any interaction between the P-dipping technique and soil types to be used for slurry and for rice cultivation.

\section{Conclusions}

Different $\mathrm{P}$ concentrations in the soil slurry and different dipping durations were investigated in order to find the appropriate P-dipping technique for transplanted rice. The results showed that the P-dipping technique promoted early growth of the transplanted rice. However, the slurry with the high $\mathrm{P}$ concentrations had a higher chance of seedling damage as a consequence of chemical injuries 
to rice seedlings during dipping, which is why it took these seedlings a longer time to recover from transplanting shock, affecting early rice growth. As longer dipping duration is not practical for farmers to follow and adopt, this study proved that a short dipping duration of $0.5 \mathrm{~h}$ is enough to enhance the early growth of rice. Our results indicated that low $\mathrm{P}$ concentrations in the slurry $\left(4.3 \% \mathrm{P}_{2} \mathrm{O}_{5}\right)$ and short dipping durations of the seedling roots $(0.5 \mathrm{~h})$ are optimal for the P-dipping technique for transplanted rice.

Author Contributions: Conceived and designed the experiments: A.Z.O., Y.T., and N.M.R. Performed the experiment: A.Z.O. Analyzed the data: A.Z.O. and Y.T. Wrote the paper: A.Z.O. and Y.T. All authors have read and agreed to the published version of the manuscript.

Funding: This work was financially supported by the Science and Technology Research Partnership for Sustainable Development (SATREPS), Japan Science and Technology Agency (JST)/Japan International Cooperation Agency (JICA) (Grant No. JPMJSA1608).

Acknowledgments: The authors would like to thank Mayumi Yonemura, Japan International Research Center for Agricultural Sciences, for conducting soil and plant analysis.

Conflicts of Interest: The authors have declared that no competing interests exist.

\section{References}

1. Fageria, N.H.; Santos, A.B.; Heinemann, A.B. Lowland rice genotypes evaluation for phosphorus use efficiency in tropical lowland. J. Plant Nutr. 2011, 34, 1087-1095. [CrossRef]

2. Nishigaki, T.; Tsujimoto, Y.; Rinasoa, S.; Rakotoson, T.; Andriamananjara, A.; Razafimbelo, T. Phosphorus uptake of rice plants is affected by phosphorus forms and physicochemical properties of tropical weathered soils. Plant Soil 2019, 435, 27-38. [CrossRef]

3. Vandamme, E.; Ahouanton, K.; Mwakasege, L.; Mujuni, S.; Mujawamariya, G.; Kamanda, J.; Senthilkumar, K.; Saito, K. Phosphorus micro-dosing as an entry point to sustainable intensification of rice systems in sub-Saharan Africa. Field Crops Res. 2018, 222, 39-49. [CrossRef]

4. Food and Agriculture Organization (FAO). Improving the Efficiency of Soil and Fertilizer Phosphorus Use in Agriculture. 2017. Available online: www.fao.org/docrep/pdf/010/a1595e/a1595e03.pdf (accessed on 2 April 2019).

5. Tsujimoto, Y.; Rakotoson, T.; Tanaka, A.; Saito, K. Challenges and opportunities for improving N use efficiency for rice production in sub-Saharan Africa. Plant Prod. Sci. 2019, 22, 413-427. [CrossRef]

6. Bayan, H.; Lourduray, A. Phosphorus management in rice and rice based cropping systems-A review. Agric. Rev. 2000, 21, 89-96.

7. Garrity, D.P.; Mamaril, C.P.; Soepardi, G. Phosphorus requirements and management in upland rice-based cropping systems. In Phosphorus Requirements for Sustainable Agriculture in Asia and Oceania, Proceedings of the International Symposium on Phosphorus Requirements for Sustainable Agriculture in Asia and Oceania, Los Baños, Philippines, 6-10 March 1989; International Rice Research Institute: Manila, Philippines, 1990; pp. 333-348.

8. Tie, Y.L.; Ng, T.T.; Chai, C.-C. Hill padi-based cropping systems in Sarawak, Malaysia. In Proceedings of the Symposium Nutrient Management for Food Crop Production in Tropical Farming Systems, Malang, Indonesia, 19-24 October 1987; Van der Heide, J., Ed.; Institute for Soil Fertility: Haren, The Netherlands; University Brawijaya: Malang, Indonesia, 1989; pp. 301-312.

9. Ros, C.; White, P.F.; Bell, R.W. Nursery fertilizer application increases rice growth and yield in rainfed lowlands with or without post-transplanting crop stress. Am. J. Plant Sci. 2015, 6, 2878-2892. [CrossRef]

10. Vandamme, E.; Wissuwa, M.; Rose, T.; Ahouanton, K.; Saito, K. Strategic phosphorus (P) application to the nursery bed increases seedling growth and yield of transplanted rice at low P supply. Field Crops Res. 2016, 186, 10-17. [CrossRef]

11. Lu, R.; Jiang, B.; Li, C. Phosphorus Management for Submerged Rice Soils. Soil Research Report No. 6; Institute of Soil Science, Academia Sinica: Nanjing, China, 1982; pp. 1-11.

12. Hooper, J.R. Progress of Research in Madagascar: Toward Identifying 75 Low Input Technological Improvements by 1995. In Proceedings of the Rice Research Seminar, Los Banos, Philippines, 4 April 1991; IRRI: Manila, Philippines, 1991. 
13. Balasubramanian, V.; Rabeson, R.; Razafinjara, L.; Ratsimandresy, J. Rice soil constraints and fertility management in the highlands of Madagascar: Fragile lives in fragile ecosystems. In Proceedings of the International Rice Research Conference, Los Baños, Philippines, 13-17 February 1995; IRRI: Manila, Philippines, 1995; p. 976.

14. Talukdar, N.C.; Thakuria, D.; Bordoloi, L.; Goswami, C. Half a decade research on utilization of soil biological agents as components of nutrient management for quality and resilience of agro and forest ecosystem. In Three Decades of Research in Biofertilizers and Organic Farming in Northeast India; Yadav, A.K., Roychoudhury, S., Eds.; Assam Agricultural University: Jorhat, India; Regional Biofertilizer Development Centre: Imphal, India, 2001; pp. 7-33.

15. Kalidas-Singh, S.; Thakuria, D. Seedling root-dip in phosphorus and biofertilizer added soil slurry method of nutrient management for transplanted rice in acid soil. J. Soil Sci. Plant Nutr. 2018, 18, 921-938. [CrossRef]

16. Murphy, J.; Riley, J.P. A modified single solution method for the determination of phosphate in natural waters. Anal. Chem. Acta 1962, 27, 31-36. [CrossRef]

17. Rakotoarisoa, N.M.; Tsujimoto, Y.; Oo, A.Z. Dipping rice roots in P-enriched slurry at transplanting significantly affects grain yield and phenology development in severely P-deficient fields in Madagascar's central highlands. In preparation.

(C) 2020 by the authors. Licensee MDPI, Basel, Switzerland. This article is an open access article distributed under the terms and conditions of the Creative Commons Attribution (CC BY) license (http://creativecommons.org/licenses/by/4.0/). 